\title{
OP CPecial Science \\ GENERAL HEALTH OF SEXUALLY ABUSED FEMALE ADOLESCENT CHILDREN IN SOUTHERN INDIA - A CAREGIVER PERSPECTIVE
}

\section{Swetha*}

Dr.Suja M. K
Mphil Scholar Department of Social Work, Bharathiar University, Coimbatore, Tamil Nadu, India *Corresponding Author

Asso.Prof \&Mental Health Professional Department of Social Work Amrita School of Engineering, Coimbatore, Amrita Vishwa Vidyapeetham, India

This research aims to study the "General Health of Sexually Abused female adolescent children from the perspective of Caregiver's. Survey research design was used for the study. The universe consisted of the caregivers of the children in the rehabilitation centres in two districts of Kerala, India. The sampling technique used for this study was Census Sampling. The sample size was 32. The tool used for the study was semi- structured interview schedule with reference to general health scale of (Rory C. Reid 2007). The findings of the study reveal that physical and mental health of sexually abused female adolescent children are affected in various ways. Children show signs of behaviour problems, sleep disturbances, loneliness and depressive traits. Many suffer from asthma which may be psychosomatic.

KEYWORDS : General health, sexual abuse, female adolescent children, Caregiver perspective, India

\section{INTRODUCTION}

In India child sexual abuse among children is one of the most prevailing problems. It is an extensive problem and even the lowest prevalence includes large number of child sexual abuse victims. The victims are mainly female adolescent children living in rural areas. The abuse has adverse effects on the physical, mental and social health of the victims. Kerala is witnessing an increase in crime against children with every passing year. Majority of children who are exposed to sexual abuse are female and are abused by someone they know - father, brother, uncle, teacher etc. This shows how vulnerable and insecure the female children are in their own home itself. There was almost 50 percent increase in the cases registered under the Protection of Children from Sexual Offences (POSCO) Act 2012. This Act was formed to protect the children who are sexually abused, sexually harassed and used for pornography and also to provide a childrenfriendly system for the trial of these offences. This Act also provides punishment for false complaint or biased information. The Act prescribes punishment according to the intensity of the offence and rigorous imprisonment for not less than ten years but which can extend to imprisonment for life.

\section{Characteristics of sexually abused children}

The behavioural and physical changes in a child can indicate the chances that the child is being sexually abused. Some children who are abused do not show these traits and some children who are never abused can show these traits. It is difficult to find out when a child is sexually abused as children will not explicitly say they are abused or they are being abused. So, it is important to notice the changes in the child's behaviour, physical health condition, mood, appearance etc.

\section{Staying away from the particular person:}

The children avoid being with the particular person, such as a family member or friend. They also feel frightened of the person or reluctant to socialise with them.

\section{Inappropriate sexual behaviour:}

The child becomes sexually active at the young age and also they have transient sexual relationships or become sex workers. They will also be using sexual language or information which is not expected to be known to them at the young age. Some try to make self as attractive as possible.

\section{Physical Symptoms:}

The children who are sexually abused will have physical health problems like anal or vaginal soreness, unable to sit comfortably or may walk with a limp, blood in urine or faeces, excessive itching or pain in the genital area. They will also have unusual discharge and sexually transmitted infections. There is also chance of some getting pregnant

\section{Behavioural Problems:}

The children may act aggressively and they will have negative feelings toward their perpetrator onto others. The children may be unwilling to engage with peers, or seem obsessed with fantasy world. They might have pain while participating in the active games and sitting during classes. The children exhibits sleep disturbances, bed wetting or frequent nightmares and eating disorders.

\section{Characteristics of caregivers of sexually abused female children:} Denial:

Parents or caretakers of sexually abused children often experience denial because it is very difficult to accept that the abuse occurred and about the after-effects. For many people it takes time to overcome this situation and face the reality.

\section{Anger:}

Sometimes the parents feel angry at themselves for not protecting their child from getting abused. They feel angry at the perpetrator for what they did. The parents sometimes feel angry at the child also.

\section{Helplessness:}

The parents do not know what to expect and feel that things are out of their control. Parents sometimes also have the fear that their children will be taken away by the system.

\section{Guilt and self-blame:}

In such situations the parents feel it is their entire fault that they did not protect and take care of their child. They also blame themselves for everything. It will take time to change this feeling of guilt of the caregiver.

\section{Impact of caregiving on caregiver:}

\section{Protective:}

Caregivers become protective about their child, ensuring that their child is close to them and they could watch over their child at all times.

\section{Emotional closeness:}

Caregivers develop a close, overinvolved and emotional relationship with the child. They become more sensitive to their child's physical, behaviour, and emotional states, especially when the child is seen crying, sad, silent or afraid.

\section{Concern about HIV status:}

This is the most important concern of caregivers of sexually abused children as their child might have contracted HIV from their perpetrator.

\section{Safety:}

Most of the caregivers are concerned about the safety of their child as their child's perpetrator is not arrested or been released on bail. The caregiver fears that the perpetrator would silence the child from testifying.

\section{General health of sexually abused children:}

The health of some sexually abused children has improved and some have become more worse than when they came to the shelter home as they are going through trauma. Some children get over it and come back to normal life but some will not be able to cope with the trauma 
and will have many mental health problems which will affect their future. Many children have more of physical health problems after the abuse. Some are affected physically after the abuse and some harm themselves physically for what had happened to them. Due to social stigma and family background some even attempt to suicide which will sometimes end up with death or rescue which will again increase the pain for the child and the family. The children in this study had more problem with their physical health and only some children are affected both mentally and physically. The health condition of the children will only improve with the support of the family, relatives, friends and also the people who are taking care of them. With proper physical and mental health support, children can come back to a healthier life.

\section{Research methodology}

The research work aimed to study the General Health of Sexually Abused Female Adolescent Children from A Caregiver's Perspective. The objective of the study was to understand the socio demographic profile of the sexually abused female adolescent children, to know the health status of the children, to find out the influence of age on variables like arguing behaviour, loneliness, temper tantrum and health. The researcher used survey design used for the study. A semi-structured interview schedule was used to collect the data. Pilot study and pre -test was done in September and December 2017 respectively. The universe consisted of sexually abused female adolescent children from two rehabilitation homes in two districts of Kerala. The identity of the centres is kept confidential because of ethical reasons. The data was collected from caregivers of 32 children by using census sampling method in the first quarter of year 2018 .

The criteria for selection of respondents was that the respondents must be the caregivers of female adolescent children in the age group from 13 to 18 years who were sexually abused. Data analysis was done for Simple percentage and chi square test were done using SPSS Version 17.

\section{Results and Discussions}

\section{Socio- Demographic profile of the children:}

Among the children $43 \%$ are of the age group 14 to 16 years. Majority $(75 \%)$ of the children are going to school. Majority $(59 \%)$ of the children have completed 6-9 years of schooling.

\section{Child's General health:}

Majority (66\%) of the children have fair health, $21 \%$ have good health and $13 \%$ have poor health. When compared to previous year it is also seen that $66 \%$ of the children have somewhat better health, $16 \%$ had somewhat worse health status, $13 \%$ had the same health status and $6 \%$ had much better health. It is seen that $41 \%$ of the children have limited socialization and have limited participation in sports activities.69\% have some limitation in playing and running. Majority (59\%) of the children are limited a lot in walking and climbing the stairs. The limitations in their physical movements may be due to their health status and mental trauma resulting from the abuse. Only $41 \%$ of the children were limited a little to taking care of themselves. $44 \%$ of the children almost never lied, cheated or had stealing behaviour.

It is seen that $50 \%$ of the children have concentration problems and $47 \%$ of children often had temper tantrums. $59 \%$ of the children have fair behaviour related to their age. $38 \%$ are satisfied withschool activities where as $34 \%$ are neither satisfied or dissatisfied with school activities and $22 \%$ are somewhat dissatisfied with activities at school. Almost half that is $47 \%$ of children were somewhat dissatisfied with family relationship. Majority ( $75 \%$ ) of the children had anxiety related problems like sleeplessness, helplessness and lack of concentration, $86 \%$ had attention seeking behaviour. $94 \%$ had behavioural problems such as aggressive behaviour, temper tantrums and engaging in fighting with peers. $78 \%$ of the children are depressed often, $88 \%$ suffer from sleep problems like insomnia, excessive sleep and disturbed sleep. $88 \%$ also suffer from vision problems and learning difficulties.

Majority of the children (53\%) had mild bodily discomfort or pain. $44 \%$ of children felt like crying often and (59\%) of them felt lonely and showed nervous behaviour. $84 \%$ had asthma problem which may also be psychosomatic due to their trauma. $84 \%$ did not have chronic allergies or sinus problems. $88 \%$ did not have chronic orthopaedic problems. Chi square test was done to find out the relationship between age and arguing behaviour, loneliness, temper tantrum and health. There is no relationship between these variables. On interacting with the caregivers it is opined that most of the children have showed improved health compared to the previous year.

\section{Conclusion \\ Implications for Social Work Practice:}

The main aim of the study was to find out the general health of sexually abused female adolescent children. Social work practice could look at educating children about the boundaries beyond which they should not allow people to come which can make things uncomfortable. Also making parents aware that they should be always available to their children. It will be also useful to create awareness of sexual abuse by collaborating with NGOs in the community. Effective measures like educating the children about safe and unsafe touch and relationship education in schools can teach them about healthy relationships which can reduce the rate of the child sexual abuse. The parents should believe their child, be fearless and raise voice against this social issue.

\section{REFERENCES:}

1. Allison, N. Sinanan. (2015). "Trauma and Treatment of Child Sexual Abuse". Retrieved from: https://www.researchgate.net/profile/Allison_Sinanan/publication/283440885 Trauma_and Treatment of Child Sexual Abuse/ links/ 58 bd d0 4545851591 c5 e9 b9
4e/Trauma-and- Treatment-of-Child-Sexual-Abuse.pdf Bak-Klimek. A., Karatzias,T., Elliott.L., \& Campbell J.(2013). "Nature of child sexual Bak-Klimek. A., Karatzias, T., Elliott.L., \& Campbell J.(2013). "Nature of child sexual
abuse and psychopathology in adult survivors: results from a clinical sample in Scotland." Journal of Psychiatric and Mental Health Nursing, 21(6), Pp 550-557.

3. Fergusson, D. M., Horwood, L. J., \& Lynskey, M. T. (1996). "Childhood sexual abuse and psychiatric disorder in young adulthood: II. Psychiatric outcomes of childhood sexual abuse." Journal of the American Academy of Child \& Adolescent Psychiatry, 35(10), 1365-1374.

4. Elizabeth, Oddone, Paolucci., Mark, L. Genuis., \& Claudio, Violato.(2010)."A MetaAnalysis of the Published Research on the Effects of Child Sexual Abuse". Journal of Psychology- Interdisciplinary and Applied, Pp 17-36.

5. Josie, Spa, Taro., Paul, E. Mullen., Philip, M. Burgess., David, L.Wells., \&Simon, A.(2004). "Impact of child sexual abuse on mental health". British journal of Psychiatry, A.(2004). "I $416-421$.

6. Kathleen, A. Kendall,Tackett., Williams, Linda M., Finkelhor, David.(1993). "Impact of sexual abuse on children: A review and synthesis of recent empirical studies". Retrieved from: https://www.ncbi.nlm.nih.gov/pubmed/8426874

7. Kristen, W. Springer., Jennifer, Sheridan., Daphne, Kuo., and Molly, Carnes. (2003) "The Long-term Health Outcomes of Childhood Abuse". Journal of General Internal Medicine, 18 , Pp 864-870.

8. Kristen, W. Springer., Jennifer, Sheridan, Daphne, Kuo, and Molly, Carnes.(2007)."Long- term physical and mental health consequences of childhood physical abuse: Results from a large population-based sample of men and women". physical abuse: Results from a large popu
Child Abuse and Neglect, 31(5),Pp517-530

9. Leah, Irish., Ihori, Kobayashi., and Douglas, L. Delahunt.(2009). "Long-term Physical Health Consequences of Childhood Sexual Abuse: A Meta-Analytic Review”. Journal of Pediatric Psychology, 18,Pp 450-461.

10. Lizette, Borelli.(2013). "Effects of Child Sexual Abuse: Depression and Other Mental Health Conditions". Retrieved from: https://www.medicaldaily.com/effects-childsexual-abuse- depression-and-other-mental-health-conditions-247591

11. Monica, D. Ulibarri., Emilio, C. Ulloa., and Marissa, Salazar.(2015). "Prevention and Outcomes for Victims of Childhood Sexual Abuse". Retrieved from: http:// europepmc. org/articles/PMC4353642

12. Mullen, P. E., Martin, J. L., Anderson, J. C., Romans, S. E., \& Herbison, G. P.(1996). The long-term impact of the physical, emotional, and sexual abuse of children: A community study. Child Abuse \& Neglect, 20(1), 7-21.

13. Paul, E. Mullen., and Jillian, Fleming.(1998)."Long-term effects of child sexual abuse". Retrieved from: https://aifs.gov.au/cfca/publications/long-term-effects-child-sexualabuse- 1998

14. Roberto, Maniglio.(2009). "The impact of child sexual abuse on health: A systematic review of reviews."Clinical Psychology Review, 29, Pp 647-657.

15. Stoltenborgh, M.van Ijzendoorn MH., Euser, E.M., Bakermans-Kranenburg M.J.(2011). "A global perspective on child sexual abuse: meta-analysis of prevalence around the world." Child Maltreat.16(2):79-101. 